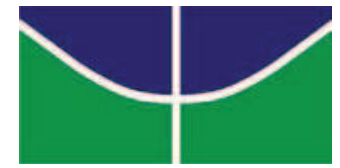

Universidade de Brasília (UnB)

Faculdade de Economia, Administração, Contabilidade e Ciência da Informação e Documentação (FACE)

Programa de Pós-Graduação em Administração (PPGA)

MARIA DE FÁTIMA FORTES DO NASCIMENTO

A CONTRIBUIÇÃO DA HOTELARIA HOSPITALAR PARA OS CLIENTES DA SAÚDE E COMO FERRAMENTA DE HUMANIZAÇÃO E MARKETING.

Brasília - DF

2010 
MARIA DE FÁTIMA FORTES DO NASCIMENTO

\title{
A CONTRIBUIÇÃO DA HOTELARIA HOSPITALAR AOS CLIENTES DA SAÚDE E COMO FERRAMENTA DE HUMANIZAÇÃO E MARKETING
}

\begin{abstract}
Monografia apresentada ao Departamento de Administração da Faculdade de Economia, Contabilidade e Ciência da Informação e Documentação - FACE, da Universidade de Brasília, como requisito parcial para obtenção do grau de Especialista em Gestão Universitária.
\end{abstract}

Orientadora: Profa . Dra. Marisa Cardoso Trindade 


\section{A CONTRIBUIÇÃO DA HOTELARIA HOSPITALAR PARA OS CLIENTES DA SAÚDE E COMO FERRAMENTA DE HUMANIZAÇÃO E MARKETING}

Monografia apresentada à Faculdade de Economia, Administração, contabilidade e Ciência da Informação e Documentação (FACE), da Universidade de Brasília, como requisito parcial à obtenção do grau de Especialista em Gestão Universitária. Data de aprovação

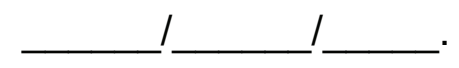

Profa. Dra. Marisa Cardoso Trindade Orientadora

Profa. Dra. Érica Negrini Lia Membro da Banca Examinadora 
Dedico este trabalho a todos que participaram do meu crescimento: Aos amigos que direta ou indiretamente me ajudaram na elaboração deste; às amigas do curso pelo companheirismo $\mathrm{e}$ amizade que construímos durante esse período. 


\section{AGRADECIMENTOS}

Tentarei, neste espaço, mostrar o meu sincero reconhecimento a todas as pessoas que me ajudaram na elaboração desse trabalho. Com toda consideração, agradeço:

A Deus, por ter me dado saúde e sabedoria que me possibilitou a realização de mais essa etapa na minha vida;

A professora Marisa Cardoso, minha orientadora nesse trabalho, pela competência profissional na orientação prestada, e, principalmente pela disponibilidade e apoio a mim concedido;

Aos professores do curso de Especialização. 
"A lei do Senhor é perfeita e refrigera a alma; o testemunho do Senhor é fiel e dá sabedoria aos símplices. Os preceitos do Senhor são retos e alegram o coração; o mandamento do Senhor é puro e alumia os olhos. O temor do Senhor é limpo e permanece eternamente; os juízos do Senhor são verdadeiros e justos juntamente". 


\section{RESUMO}

Esse trabalho de conclusão de curso aborda a contribuição da hotelaria hospitalar aos clientes da saúde e como uma ferramenta de humanização e marketing nas instituições de saúde da atualidade. Devido à nova exigência do cliente da saúde, que não busca somente médicos renomados no mercado ou equipamentos médicohospitalar de alta tecnologia para o tratamento da patologia que possui - busca e exige um tratamento com atenção, carinho e presteza por parte de toda equipe, ou seja, um tratamento hospitalar humanizado. Para isso ações e serviços de uma hotelaria clássica adaptados ao ambiente hospitalar foram expostas, a fim de conscientizar todos os colaboradores e gerência sobre a sua importância. Esse trabalho aborda ainda os conceitos de hotelaria hospitalar e sua implantação em alguns hospitais no Brasil. Para tal foi realizada uma pesquisa bibliográfica, enfocando a humanização e a hospitalidade, onde, conclui-se, que tais ações contribuem eficazmente no tratamento médico e na cura do paciente.

Palavras Chave: Hotelaria hospitalar, clientes da saúde, humanização, hospitalidade. 


\section{SUMÁRIO}

1 - INTRODUÇÃO 10

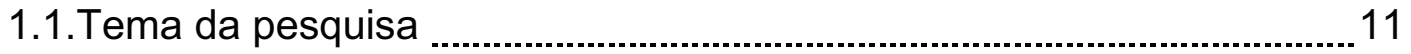

1.2. Delimitação do Tema ………………………………………………... 11

1.3. Problema da pesquisa

1.4. Formulação do problema da pesquisa ................................................. 13

1.5. Objetivos $\ldots$

1.5.1. Objetivo geral

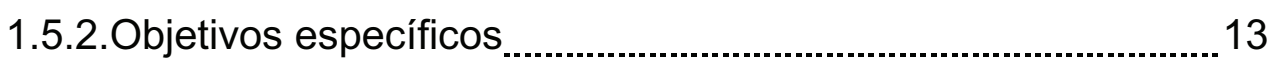

1.6. Justificativa

2 - REFERENCIAL TEÓRICO

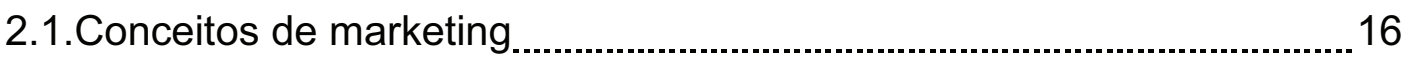

2.2. Marketing aplicado à saúde pública ....................................................... 17

2.3. Conceituando hotelaria hospitalar .......................................................... 18

2.4. Hospitalidade

2.5.0 desafio das mudanças nas instituições de saúde pública ..................22

2.6. Situação atual da hotelaria hospitalar no Brasil ......................................24

2.7. Humanização através dos serviços de hotelaria hospitalar .................... 26

2.8. Sinergia entre hotelaria hospitalar e psicologia hospitalar .................... 28

2.8.1 Similaridades entre a psicologia e hotelaria hospitalar........... 31

2.9. Gastronomia hospitalar $\ldots$

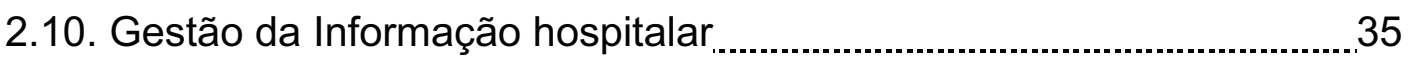

2.11. Setores e departamentos dentro dos hospitais ......................................36

2.11.1. Lavanderia hospitalar ................................................................... 37

2.11.2. Operacionalização da lavanderia hospitalar ...................................... 38

2.11.3. Departamento de Recepção e hospedagem .................................... 40

2.11.3.1. Atribuições e responsabilidades .......................................... 41

2.11.4. Departamento de segurança e portaria ............................................... 42

2.11.5. Departamento de A e B (Alimentos e Bebidas) .................................. 43

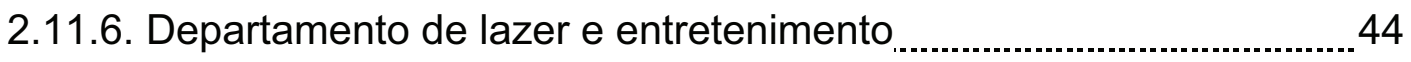




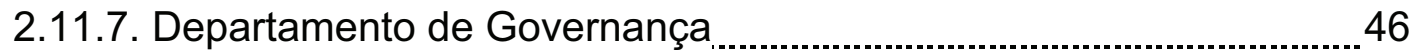

2.12. Quebrando paradigmas .............................................................. 47

2.13. Hotelaria hospitalar: Investir para sobreviver ...................................47

3. METODOLOGIA

3.1.Tipo de pesquisa

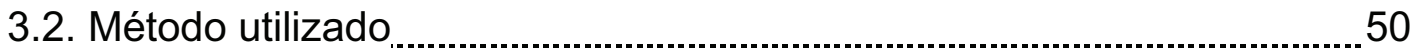

4. CONCLUSÃO

5. REFERÊNCIAS BIBLIOGRÁFICAS 


\section{INTRODUÇÃO}

O tema deste trabalho refere-se à contribuição da hotelaria hospitalar aos clientes da saúde e como ferramenta de humanização e marketing. Destaca-se que a hotelaria hospitalar é uma nova tendência que agrega tecnologia, ciência, conforto e segurança na hospitalidade, oferecendo qualidade, valor e satisfação para o cliente. Este novo segmento tem a função de contribuir no aprimoramento do sistema hospitalar, que deve ser o resultado de matéria, trabalho e valores.

Segundo Figueiredo (2003), "o ambiente hospitalar não é mais o lugar limitado em que o paciente ficava quando hospitalizado". As pessoas vivem em um mundo que é um grande sistema aberto, onde fazem trocas e se relacionam com os outros. Portanto, enquanto hospitalizado, o ambiente do cliente é o seu mundo e não pode ser restrito, devendo proporcionar a sensação de relacionamento com esse mundo e não de isolamento.

Também podemos dizer que somente a aquisição de aparelhos médicohospitalar de alta precisão diagnóstica e os cuidados básicos físicos diários com o cliente não são suficientes para satisfazê-lo. O hospital evoluiu, bem como também as exigências do cliente e do mercado. Cada hospital ou qualquer organização de saúde precisa ser competitivo e, para isso, é indispensável oferecer ao cliente um diferencial que o atraia.

Para criar e tornar esse ambiente atraente, agradável e confortável torna-se necessário investigar os hábitos, as necessidades e as expectativas do cliente como, por exemplo, o tipo de música, de programa de televisão, religião, horário que costuma fazer sua higiene pessoal, horário de alimentação e o que gosta de comer, seu lazer preferido. Essa investigação permite um diagnóstico de suas necessidades e desejos.

Essa idéia tem se tornado gradativamente de grande importância. Muitos teóricos contribuíram e contribuem para a idéia de um cliente que não deixa de ser humano. Nesse sentido, podemos destacar Maslow. De acordo com esse autor o homem tem necessidades inerentes à sua condição humana e que obedecem a uma hierarquia. A primeira categoria delas são as necessidades básicas ou de sobrevivência, dentre as quais pode-se destacar a necessidade de abrigo. Percebese que o paciente hoje está mais atento e conhecedor de seus direitos, assim ele questiona e exige da instituição hospitalar, não só a cura ou tratamento, mas 
conforto e bem estar; e isso é um fator que reforça a criação do conceito de hotelaria hospitalar.

O ambiente hospitalar já era preocupação da criadora da enfermagem científica Florence Nightingale: a circulação do ar não deveria ser apenas adequada, mas agradável; a iluminação não podia incomodar o cliente; os ruídos precisavam ser suavizados e a limpeza devia ser adequada; as roupas precisavam ser limpas e cheirosas.

Nesta variável competitiva, o marketing se transformou em importante ferramenta das redes hospitalares, porque além de permitir a criação e a adaptação de serviços para atender de forma satisfatória a expectativa e a necessidade do público alvo, é capaz de alavancar a humanização.

Este trabalho traz uma análise reflexiva sobre as contribuições e os benefícios da hotelaria hospitalar para as instituições de saúde e, principalmente para os seus clientes (pacientes), bem como ressaltar a importância da conscientização dos gestores de que a hotelaria a ser implantada é adaptada, e, não, a hotelaria clássica, visto que sua adaptação é obrigatória, considerando as características peculiares das atividades hospitalares que não comporta vícios e hábitos, que na hotelaria convencional são aceitáveis.

\subsection{Tema da pesquisa}

A contribuição da hotelaria hospitalar aos clientes da saúde e como ferramenta de humanização e marketing

\subsection{Delimitação do tema}

O estudo limita-se a uma pesquisa bibliográfica realizada nos meses de maio a dezembro de 2009, e se restringe à exposição e análise dos conceitos pesquisados em livros, artigos, Manual de Humanização do Ministério da Saúde, internet. Em seguida, mostra os serviços que a hotelaria hospitalar oferece aos clientes da saúde, sua influência na atividade curativa, bem como sua importância como ferramenta de humanização nos hospitais, tanto na rede pública quanto na rede privada. 


\subsection{Problema de pesquisa}

A tecnologia de ponta e as melhores estruturas físicas hospitalares andam na contramão da hospitalidade e carinho dispensados aos doentes na grande maioria dos hospitais (CAMARGO, 2002)

Os hospitais são instituições consideradas complexas de serem administradas e a despeito de seus esforços, carecem de uma estrutura física e humana menos traumática ao paciente, podendo tornar a hospitalidade como um agente fomentador de calor humano, em contraste com a frieza do ambiente hospitalar. "A hospitalidade pode e reduz radicalmente o sofrimento de pacientes e clientes, minimizando a dor para pacientes e familiares em momentos de dor e fragilidade " (GODOI, 2004).

Segundo o Manual de Humanização do Ministério da Saúde, o Programa Nacional de Humanização da Assistência Hospitalar (PNHAH), oferece uma diretriz global que tem caráter humanizador estimulando a criação e a sustentação permanente de espaços de comunicação que facultem e estimulem a livre expressão, a dinâmica do diálogo, o respeito à diversidade de opiniões e a solidariedade nas diversas áreas de atendimento hospitalar, tendo como um dos seus objetivos modernizar as relações de trabalho no âmbito dos hospitais públicos, tornando as instituições mais harmônicas, flexivas e solidárias.

Hoje, os estudiosos de administração de serviços já relacionam a hospitalidade como um valor que toda empresa deveria cultivar, a fim de anteciparse às necessidades dos clientes. O momento é de propor além do tempo, surpreendendo o cliente, antecipando-se em oferecer serviços além do que ele esperava. Cabe, então, ao serviço de Hotelaria Hospitalar se desdobrar para oferecer um serviço cotidiano qualificado que atenda às necessidades e os desejos do cliente.

Pensando em melhor atender o cliente da saúde, a hotelaria hospitalar surge como uma nova proposta às instituições de saúde, onde o cliente não mais busca somente por médicos renomados, e equipamento médico-hospitalar de última geração; ele exige um atendimento humanizado que se encontra facilmente em hospitais que já implantaram a hotelaria hospitalar.

O presente trabalho trata da contribuição dos serviços de uma hotelaria hospitalar, em como estes quando implantados elevam a qualidade do atendimento 
médico-hospitalar e das instalações que são colocadas à disposição de pacientes, familiares e visitantes, bem como dos profissionais que atuam dentro do hospital.

\subsection{Formulação da questão da pesquisa}

Hoje o mercado é cada vez mais competitivo e a velocidade de informações e de mudanças são partes do cotidiano de qualquer empresa. O Hospital, sendo inserido neste contexto, além de atender aos aspectos físicos deverá, principalmente, estar atento ao aspecto humano - como hospitalidade no atendimento - para ter maior êxito no mercado globalizado.

Assim, neste trabalho de estudos e pesquisa pretende-se responder à seguinte questão: na percepção de diferentes autores e estudiosos, qual a efetiva contribuição da hotelaria hospitalar para os clientes da saúde e como ferramenta de humanização e marketing?

\subsection{Objetivos}

\subsubsection{Objetivo Geral}

Pesquisar, segundo a percepção de diferentes autores e estudiosos da temática, qual a efetiva contribuição da hotelaria hospitalar para os clientes da saúde e como ferramenta de humanização e marketing.

\subsubsection{Objetivos Específicos}

- Conceituar Marketing

- Conceituar Marketing aplicado à Saúde Pública

- Conceituar Hotelaria Hospitalar;

- Descrever os valores e ações humanas agregados ao tratamento dispensado às pessoas recebidas como hóspedes, através dos serviços de Hotelaria Hospitalar; 


\subsection{Justificativa}

Os principais motivos de ordem prática, que levaram a elaboração deste trabalho foram a necessidade de discussão sobre a contribuição da hotelaria hospitalar para a instituição de saúde em que estou inserida, devido a percepção da falta de ações e valores humanos.

Baseada nas experiências vivenciadas no Hospital Universitário de BrasíliaHUB, por duas décadas, e, diante da percepção da carência concernente ao atendimento/hospitalidade, percebeu-se a importância dos serviços de hotelaria adaptados à área da saúde. Por se tratar de uma temática inovadora a hotelaria hospitalar é um desafio para as instituições de saúde públicas, principalmente o HUB.

O HUB, anteriormente conhecido como Hospital Docente Assistencial, em 1990, foi cedido à Universidade de Brasília em ato assinado pelo presidente Fernando Collor e passou a se chamar Hospital Universitário de Brasília (HUB).

O HUB possui importante participação na tríade - assistência-ensino pesquisa, destacando-se como um dos mais importantes pólos formadores de recursos humanos na área da saúde da região Centro-oeste. É, portanto, uma instituição de saúde renomada e referencial nacional na qualificação técnica de seus profissionais. Entretanto o hospital pode ser excelente no tocante à tecnologia e qualificação profissional e ser desumano na forma de atendimento e no acolhimento da hospitalidade. Pensamos que a hospitalidade e a qualidade no atendimento ao cliente da saúde deverão, também, andar paralelamente aos avanços tecnológicos e a modernidade. Consideramos que o incremento e a implantação da hotelaria hospitalar atuam como uma ferramenta de humanização e marketing, entendemos que as instituições de saúde precisam introduzir ações inovadoras, serviços e condutas diferenciados no processo da hospitalidade, para garantir o sucesso e o destaque de uma diferenciação.

Há a necessidade de inserir nas instituições de saúde um sistema de hotelaria que se adapte à nova realidade do mundo globalizado, que vise atender com qualidade, flexibilidade e humanização ao novo perfil do cliente da saúde, que tem mostrado -se mais exigente, crítico e inteligente. Assim, cresce em importância o fenômeno a ser pesquisado. $O$ fato de a hotelaria hospitalar ser um assunto novo, pouco explorado torna-a, portanto, um desafio para as instituições de saúde, 
colaboradores e futuros estudos deste novo segmento que procura mudar o conceito antigo dos serviços hospitalares.

A abordagem dessa nova tendência poderá contribuir para promover o debate sobre o tema no HUB e propiciar uma reflexão sobre a implementação de uma hotelaria hospitalar e os seus conseqüentes benefícios. Isto, tanto para o cliente da saúde quanto para as instituições onde se destacam a qualidade, a segurança e a humanização na hospitalidade. Além disso, saber como estes afetam, positivamente, o atendimento como um todo nos hospitais e, indiretamente, permitir que seus leitores possam ter uma compreensão a cerca dos conceitos de hotelaria hospitalar, bem como da necessidade de implantação desses serviços no HUB. 


\section{REFERENCIAL TEÓRICO}

\subsection{Conceitos de Marketing}

Segundo Kotler (2006), "marketing é a entrega de satisfação para o cliente em forma de benefício". Ou seja, é olhar para o que o cliente necessita, gosta, quer e o satisfaz, criando valor para este.

É comum ouvirmos pessoas atribuindo ao marketing rótulos pejorativos em algumas circunstâncias de venda e propaganda. Embora estas pessoas possam estar enganadas quanto ao sentimento ruim associado ao marketing, elas estão certas quando relacionam-no a venda e propaganda. Contudo, o "papel do marketing na saúde é atuar preventivamente no sentido de identificar necessidades de atendimento e indicar procedimentos" MORAES, et al ( 2004).

Vários paradigmas estão sendo quebrados principalmente na área hospitalar. Os conceitos de marketing têm sido nos últimos anos, utilizados cada vez mais na área da saúde. No esclarecimento da população quanto aos cuidados da prevenção de doenças, na busca de satisfação, na oferta de um novo tipo de assistência, enfim na comunicação e desenvolvimento de novos serviços e na melhoria gradativa daqueles, já prestados.

Geralmente, na saúde, o marketing não tem por função criar demanda, mas sim administrá-la de forma a buscar a satisfação das necessidades e carências da população, através do uso racional dos recursos disponíveis. O mais importante nesta área é identificar as demandas de um grupo específico de pessoas não atendidas e gerar produtos e serviços de qualidade para atendê-las. A finalidade do marketing na área hospitalar é implementar um programa, que priorize: estudos para criação ou adaptação de serviços para atender a necessidade do público alvo, desenvolvimento de parcerias e divulgação do trabalho.

Considera-se que os conceitos de marketing tenham chegado aos hospitais da mesma forma que a comunicação e a qualidade em produtos e serviços; tudo é utilizado como fórmulas para melhorar os processos. Dentre os diversos conceitos de marketing, cita-se: 
O marketing é um processo social e gerencial por meio do qual os indivíduos e os grupos obtêm aquilo de qual precisam e também o que desejam, em razão da criação e da troca de produtos e serviços de valor com outras pessoas. (KOTLER et al., 2002).

O entendimento do comportamento dos clientes e a criação de um canal de comunicação do hospital que deseja, por exemplo, integrar-se socialmente à comunidade, visando no fortalecimento da imagem, é uma das ações que o marketing pode fornecer com segurança para, a partir daí, serem estabelecidos fatores para decisões futuras.

Segundo Moraes et al (2004), o marketing em saúde ocupa lugar de destaque, e são muitas as razões que justificam a sua aplicação:

- É possível antecipar as ações no sentido de atender aos anseios dos clientes e da comunidade que o hospital integra;

- O gerente da hotelaria hospitalar tem melhores perspectivas para bem gerir o atendimento hospitalar diferenciado;

- Existem condições de pesquisar com segurança os anseios de um cliente da saúde e satisfazê-lo plenamente;

- Poderá constituir-se no diferencial ante a concorrência e fixar-se no mercado.

Entendemos que a aplicação do marketing na saúde possibilita atender, criar e gerenciar aquilo que o cliente deseja; possibilitando a realização de pesquisa para identificar as necessidades dessas pessoas com as quais a instituição hospitalar estabelece relação comercial.

\subsection{Marketing aplicado à Saúde Pública}

De acordo com kotler,(2006) o conceito mais básico e inerente ao marketing aplicado à saúde pública é o marketing social que é a gestão estratégica do processo de introdução de inovações sociais, a partir da adoção de comportamentos, atitudes e práticas, individuais e coletivas.

Marketing aplicado à saúde pública consiste um programa público do ponto de vista do consumidor (membro da unidade/cliente/paciente) e, que mesmo estando em sua infância mostrou ser bastante efetivo em direcionar alguns problemas de saúde pública (MORAES et al, 2004). 
Outro conceito de marketing, "é a função organizacional e um conjunto de processos que envolvem a criação, a comunicação e a entrega de valor para os clientes, bem como a administração do relacionamento com eles, de modo que beneficie a organização e seu público interessado" (AMA, 2005).

Já na opinião de Schiavo ( apud MCCARTHY 2003) marketing na saúde pública é um processo social que dirige o fluxo de bens e serviços dos produtores para os consumidores, de maneira a equilibrar efetivamente a oferta e a procura, a fim de alcançar os objetivos da sociedade. O marketing hospitalar tem se constituído em uma importante ferramenta que dinamiza, atualiza e fundamenta a gestão administrativa. Essa questão deveria estar presente nos hospitais que desejam competir e galgar o sucesso.

\subsection{Conceituando hotelaria hospitalar}

Hotelaria hospitalar é a introdução de técnicas, procedimentos e serviços de hotelaria em hospitais como o conseguinte benefício social, físico, psicológico e emocional para pacientes, familiares e funcionários (GODOI, 2004,).

O estudo da hotelaria hospitalar torna-se importante a partir do momento em que os clientes da saúde (pacientes) começaram a reivindicar os seus direitos e questionar a qualidade do atendimento de todos os funcionários que compõe os ambientes de saúde. A hotelaria hospitalar não é prerrogativa apenas de hospitais particulares, existindo também em hospitais públicos, cujas iniciativas individuais, percebe-se, têm minimizado a dor e o sofrimento de uma grande parcela da população que se vê abandonada nos momentos mais difíceis de suas vidas.

O conceito de hotelaria hospitalar é recente no Brasil, porém sua evolução tem sido rápida. O principal motivo deste crescimento é que a hotelaria passou a ser vista como um diferencial, pois os clientes passaram a buscar não só o tratamento ou a cura de uma enfermidade, mas uma instituição de saúde que também ofereça conforto, segurança e comodidades. "A hotelaria hospitalar está com serviços muito próximos ao de um hotel, com uma clientela com necessidades diferencias e com um grau de sensibilidade muito maior ao ambiente" (GODOI, 2004).

Portanto, agregar serviços oferecidos em hotéis a esse público tornará sua convalescença menos traumatizante e menos desgastante. Forma-se uma nova imagem de hospital: aquele que não existe apenas para tratar doenças, mas para 
promover qualidade de vida, produzir conhecimento e vender o principal serviço, a saúde.

Na definição de Boeger (2005) a hotelaria hospitalar, consiste na reunião de todos os serviços de apoio, que associados aos serviços específicos, oferecem aos clientes internos e externos conforto, segurança e bem-estar durante seu período de internação. Já Cândido et al (2004) definem hotelaria hospitalar como:

A prática de serviços e atividades que visam ao bem-estar, ao conforto, à segurança, à assistência e à qualidade no atendimento a clientes da saúde, representados por pacientes e acompanhantes, desde seu check-in até seu completo check-out em um hospital.

O novo conceito de hotelaria hospitalar surge com a necessidade da busca de excelência na prestação de serviços que agreguem valor ao cliente, visto agora como um cidadão com direitos a serem respeitados, Ainda não completamente estruturada, sua composição varia, mas os objetivos são comuns: proporcionar conforto, segurança e bem estar ao cliente interno e externo, através da transformação do ambiente hospitalar, para torná-lo mais acolhedor.

A preocupação com a busca de excelência, segundo Guimarães (2007), é resultado das pressões originadas dos próprios usuários (clientes externos), dos grupos de medicina privada e da equipe multidisciplinar (cliente interno), fazendo com que esse conceito de hotelaria hospitalar saia da teoria para a prática no dia-adia". Por ser uma área ainda em processo de estruturação, a sua composição varia de uma organização de saúde para outra, mas, de um modo geral, seus serviços constituem-se em: higiene e limpeza, lavanderia e rouparia, recepção, unidade de nutrição e dietética, restaurante ou cafeteria, loja de conveniência, jardim, estacionamento, segurança patrimonial e das pessoas, manutenção dos apartamentos e áreas de circulação.

Cada um desses serviços deve contribuir para o alcance dos objetivos organizacionais, oferecendo conforto e comodidade ao cliente, o que certamente potencializa o resultado obtido através do tratamento médico e da assistência de enfermagem. Contudo, uma prestação de serviços que satisfaçam às necessidades e até superem as expectativas do cliente só será alcançada se os profissionais que trabalham na organização hospitalar tiverem condições de trabalho e ambiente adequado. Além disso, precisam de capacitação e atualização contínua. É papel do 
serviço de educação permanente prover condições para o desenvolvimento dos colaboradores, não só no aspecto profissional, mas também no aspecto pessoal.

\subsection{Hospitalidade}

Ao se falar da hotelaria hospitalar, não podemos deixar de fazer referência à hospitalidade e à humanização na assistência hospitalar.

Segundo Ismael (2005), a hospitalidade é a generosidade de um agrupamento humano, seja uma comunidade, etnia, cidade, nação, estado ou pais. É a ternura do povo de um lugar em relação ao estrangeiro e os seus mistérios, enquanto este também imagina os seus anfitriões como uma gente misteriosa e nem por isso deixou de visitá-la; ou seja, hospitalidade, sob qualquer de suas formas, compreende essencialmente a prestação, gratuita ou não, de serviços obtidos normalmente por uma pessoa em seu próprio lar, mas que, por não possuí-lo, ou por estar dele ausente temporariamente, não os tem a disposição.

Quando a hospitalidade proporciona acomodações para repouso e deleite, caracteriza-se a hospedagem, acompanhada ou não de refeições. "Se apenas estas são fornecidas, existira hospitalidade, porém não hospedagem” (BOEGER, 2005).

Ainda segundo Ismael (2005). Nessa denominada "cadeia da acolhida" (boas vindas, atenção dada durante a estadia e despedida) o hóspede ou paciente precisa estar encantado para então considerar sua hospitalidade de boa qualidade.

É importante que o paciente tenha um acolhimento cortês e o mais parecido possível com o seu ambiente familiar, pois precisam sentir-se em casa. Para isso, os profissionais precisam criar ambientes agradáveis, e é nesse momento que a hotelaria hospitalar faz o seu papel; oferecer um acolhimento caloroso que deve ser exercido por todos os funcionários ligados à instituição desde a chegada, durante a sua estadia até a sua alta hospitalar.

Os avanços científicos e tecnológicos dos serviços da área da saúde, assim como o desenvolvimento do conhecimento da ciência que cuida do ser humano, são visíveis. Os sofisticados aparelhos tecnológicos, as técnicas cirúrgicas cada vez mais avançadas, a variedades de medicamentos e o desenvolvimento de ações da medicina preventiva são alguns exemplos. Esta evolução nem sempre tem sido acompanhada na atenção ao cliente. O contato pessoal entre o cliente e o colaborador ainda necessita ser aprimorado, principalmente nos hospitais da rede 
pública, onde o número de queixas é elevado em relação à qualidade do atendimento (GUIMARÃES, 2007).

A falta de clareza nas informações dadas acaba sendo responsável na maior parte das vezes pelo mau atendimento. As diferenças individuais devem ser consideradas e o bom senso deve estar presente nestas ocasiões. Na opinião de Guimarães, (2007) é importante o profissional conhecer o perfil sociodemográfico da população atendida e identificar a capacidade cognitiva do cliente externo. Com essa atitude estará evitando o ir e vir por falta de entendimento das orientações e informações recebidas. Nesse momento, para a agilização do atendimento é importante a interação entre cliente e colaboradores, por meio da comunicação verbal e da postura profissional.

É comum presenciarmos nos hospitais públicos a falta de ações de humanização e de qualidade no atendimento, o que isso muitas vezes é alvo de críticas de seus clientes (usuários). Preocupado com essa situação o Ministério da Saúde criou em 2001 o Programa Nacional de Humanização da Assistência Hospitalar (PNHAH), com o objetivo de mobilizar diferentes hospitais que sistematizaram seu atendimento com a criação de programas e projetos de humanização hospitalar.

Na opinião de Guimarães (2004), na hotelaria hospitalar o oferecimento de serviços deve conter na sua execução, a dedicação de quem o presta, atenção e respeito ao cliente e o pleno atendimento às suas expectativas, buscando permanentemente sua satisfação e encantamento, considerando os seguintes aspectos:

- Preservar a identidade do cliente

- Respeitar seus hábitos de vida e cultura

- Não expor o cliente a regras e normas impostas de cima por um sistema explícito de regulamentos

- Interpretar as normas e rotinas do hospital

- Preservar o contato familiar

- Propiciar atendimento integral ao cliente

- Acolher o cliente no ambiente hospitalar

- Interagir com o cliente de forma hospitaleira. 


\title{
2.5. O desafio das mudanças nas instituições de saúde pública
}

A implantação da hotelaria nos hospitais públicos encontra muita resistência devido a sua própria cultura, é algo ainda difícil de alcançar quando comparado aos hospitais privados.

A implementação da hotelaria hospitalar parcialmente ou na sua plenitude parece ser algo difícil para os atuais administradores, que se sentem receosos de implantá-la, devido ao fato dessas mudanças se situarem entre dois extremos: o sucesso e a crítica social (GODOI, 2004).

A péssima comunicação entre as áreas administrativas, a insatisfação do cliente e ausência de um atendimento de qualidade e humanizado, são fatores que ainda estão presentes nos hospitais públicos e precisam ser erradicados.

Na opinião de Godoi a implantação de mudanças nos hospitais normalmente encontra resistência para adaptação:

\begin{abstract}
A dificuldade de inserir novos comportamentos e novas tendências administrativas dentro de hospitais, encontra resistência na grande maioria das instituições públicas, entre outros motivos arrazoa-se o receio de descaracterizar o hospital com novos padrões de atuação (GODOI, 2002, p. 31).
\end{abstract}

Para mudar esse cenário, as instituições precisam estar preparadas para enfrentar mudanças que acontecem em seus ambientes, cada vez com mais freqüência e em ciclos mais curtos, provocados principalmente por: pressões por melhores resultados e utilização dos recursos, exigência do público alvo, exigência sobre a educação, segurança e qualidade de vida, grandes desafios oriundos da globalização e impactos sobre o trabalho, comunicação e avanços tecnológicos.

Hoje, através de leituras, de visitas e de propaganda temos conhecimento de alguns hospitais particulares cujos gestores ousados e preocupados com a hotelaria hospitalar, implantam mudanças arquitetônicas, programação social, serviços de hotelaria com capitão-porteiro e mensageiros devidamente uniformizados e equipados para a recepção do cliente da saúde, quadros em exposição, música ambiente, restaurante, piano-bar e apresentação de músicos dão a impressão de se ter errado de endereço. Quem entra pelo saguão de alguns hospitais particulares tem a sensação de estar num ambiente de hotel de primeira linha. Macas, clientes 
de saúde aglomerados à espera de atendimento, cadeiras de rodas enfileiradas, ambiente frio e com cheiro de éter são cenas do passado.

Segundo Taraboulsi (2009), existe uma grande dificuldade e resistência na aceitação das mudanças:

\begin{abstract}
Uma das maiores dificuldades das instituições de saúde sempre foi e continua sendo a incapacidade de seus gestores em visualizar o leque de entes que a expressão "cliente da saúde" abrange. Precisamos ter a consciência da necessidade de autocrítica em relação a certos princípios e definições que herdamos sem, ao mínimo, analisar seu conteúdo, tornandonos reféns de paradigmas que nos vedaram os olhos e inibiram a nossa sensibilidade e inteligência (TARABOULSI, 2004, p.23).
\end{abstract}

Precisamos, então, ter o firme propósito de nos libertarmos desses cárceres de visão limitada e estática que representa por si um significativo avanço e nos leva a perceber quão distantes estamos da realidade.

Segundo o manual de humanização do Ministério da Saúde (2006), o objetivo do Programa Nacional de Humanização da Assistência Hospitalar é criar uma cultura de humanização, partindo do que já é feito nesse sentido, criar uma filosofia organizacional que promova a conjugação cotidiana do verbo humanizar. A preocupação é com a continuidade da humanização da assistência hospitalar que supere as descontinuidades que as mudanças de direção, chefia ou governo geralmente provocam. Entendemos que uma cultura de humanização leva tempo para ser construída e envolve a participação de todos os atores do sistema. E como refere o manual: "humanizar é verbo pessoal e intransferível, posto que ninguém pode ser humano em nosso lugar. E é multiplicável, pois é contagiante". Ou seja, humanizar é um verbo que precisa ser conjugado continuadamente por um número cada vez maior de usuários e trabalhadores da saúde, pois facilmente se desgasta e vira desumanização.

Preocupados com o estado físico e emocional do cliente de saúde e, principalmente com as internações prolongadas e as horas gastas por familiares e amigos em recintos que parecem mais com muros de lamentações do que salas de espera, alguns gestores estão tentando deixar para trás a imagem tradicional de hospital, levando para suas instituições mudanças e serviços que minimizam o impacto desses momentos difíceis, transformando a estada no ambiente hospitalar mais agradável, afinal as pessoas nunca terão prazer de estar no hospital, mas o desconforto pode ser minimizado (TARABOULSI, 2009). 
Observa-se que esta nova tendência que traz em sua essência a humanização do ambiente hospitalar, precisa contagiar, também, os hospitais públicos e outros cuja fatia de participação de clientes de saúde do SUS é bastante representativa. Serviços de hotelaria, plantas espalhadas pesas áreas sociais, jogos, aulas de dança e de arte, peças de teatro e filmes, pessoas de todas as classes sociais dividem espaços de televisão, leituras e brinquedos, aulas de alongamento e apresentações musicais para combater o estresse dos familiares e acompanhantes, coral próprio com a participação de empregados, médicos e voluntários e muitas outras atividades de cunho humano e motivacional.

Segundo depoimento colhido de alguns gestores, psicólogos e médicos, essas necessidades de mudanças não estão acontecendo por acaso, pois está em curso um novo perfil de clientes que as exigem. Este novo cenário pode parecer para muita gente luxo desnecessário e esforço inútil, mas a receptividade dos clientes de saúde ao tratamento e a satisfação observada facilitaram muito o serviço médico e diminuíram consideravelmente os quadros depressivos.

\subsection{Situação atual da hotelaria hospitalar no Brasil}

País considerado hospitaleiro, o Brasil não tem a tradição na formação de profissionais para o setor da hospitalidade. Até a década de 90, existia uma ou outra escola que abordava o assunto de forma séria e eficiente, mas mesmo essas escolas não ofereciam aulas sobre "atendimento". Tratamos o atendimento como algo inerente a cada pessoa, embora seja uma qualidade que deve ser polida em cada um.

Se observarmos na história do Brasil, o "servir" sempre foi visto de forma pejorativa. Contudo consideramos que o "servir" é mais que uma arte; é qualidade na prestação de serviço, e o atendimento é de vital importância para uma instituição ou estabelecimento. Os critérios inerentes a cada pessoa devem ser estabelecidos no recrutamento e o atendimento deve ser de forma diferenciada no mercado. As instalações estão se padronizando, os avanços e as facilidades tecnológicas estão ao alcance de todos, mas o grande diferencial continua não podendo ser padronizado: o atendimento, a chave para a excelência na prestação de serviços.

O atendimento é forte aliado do sucesso e deveria ser tratado de forma diferenciada pelos profissionais. A partir do momento que o ato de "servir" deixe de 
tornar uma forma subserviente e pejorativa e passe a ser tratado com um estado da arte, passaremos a encontrar serviços de hotelaria hospitalar e redes com "tradição", o que ainda não ocorre totalmente no nosso país.

O Brasil começa a investir na hotelaria hospitalar, como empresa bem sucedida a partir do ano de 2000. Segundo Guimarães (2007, p.2), esse conceito de hotelaria hospitalar não está totalmente incorporado, uma vez que os profissionais de saúde logo associam hotelaria com conforto e modernas acomodações, deixando de lado todo o restante dos serviços de apoio que compõem o atendimento ao cliente.

De acordo com alguns especialistas em hotelaria hospitalar, este conceito nasceu há 10 anos aproximadamente, e hoje é entendido como modelo de gestão que equipara os hospitais em termos de estrutura física e serviços e que esse modelo de gestão não será usado somente pelos hospitais particulares, atualmente já existem hospitais da rede pública que implantaram, ou estão tentando implantala. Porém muitos hospitais públicos, comparados com os privados, enfrentam dificuldades adicionais devido à falta de verba, mas alguns ainda conseguem desenvolver trabalhos tão bons quanto os privados usando a criatividade e competência. Verifica-se que esses hospitais, por meio de seus profissionais de serviços de apoio, demonstram interesse em desenvolver os serviços de hotelaria hospitalar, ou seja, a questão não depende somente do hospital, mas sim da visão de seus administradores.

Em alguns hospitais que estão vencendo, tanto a concorrência como as suas próprias deficiências e conceitos ultrapassados, pacientes e acompanhantes já estão sendo tratados como hóspedes e percebem, logo na chegada, que algo mudou em relação às expectativas que tinham quando de uma internação hospitalar (MORAES, 2004).

Dessa forma alguns hospitais aderiram à práticas não convencionais em hospitais tradicionais. Além de alterarem a aparência do hospital na entrada, dandoIhe um aspecto de hotel, implementaram ambientes destinados ao lazer e à cultura. Há hospitais que dispõem de salas onde apresentam concertos; outros como o hospital Albert Einstein em São Paulo possui no átrio uma galeria de arte aberta 24 horas com acesso livre, ou seja, tem um espaço cultural onde acontecem diversas exposições de arte. Quiosque com café, grupo de música, duas lojas de 
conveniência, sala para meditação e dois restaurantes como parte da infra-estrutura de suporte ao paciente e seus familiares (GODOI, 2004).

O hospital Mãe de Deus, em Porto alegre, foi criado um espaço com bar, mesas e cadeiras tradicionais de bar e um piano. Em determinados horários um pianista executa músicas especiais próprias para relaxamento e conforto dos pacientes e acompanhantes.

Já o Hospital Oswaldo Cruz, no Rio de Janeiro, possui em seu salão de chá jardins belos no entorno favorecendo o contato do paciente com a natureza, fator este que, segundo Godoi (2004) é despercebido nas grandes cidades e que tem um importante papel na recuperação do doente.

Os berçários, em alguns hospitais estão localizados em áreas privilegiadas, como é o caso do Hospital São Paulo, em Teresina - PI . Os bebês são observados através de um vidro duplo que isola os ruídos externos, que dá para um terraço do tipo jardim de inverno com mesas e cadeiras, imitando uma lanchonete; ali os pais, padrinhos e familiares podem apreciar as primeiras reações dos recém-nascidos.

Além do impacto pela aparência física dos novos hospitais, clientes, pacientes e acompanhantes estão se encantando com a nova modalidade de recepção por parte dos atendentes: são verdadeiros recepcionistas de grandes e bons hotéis. Esse referencial está se constituindo em uma significativa e real mudança que vende, acolhe bem e dá outro enfoque à realidade de uma internação (MORAES, 2004).

\subsection{Humanização através dos serviços de hotelaria hospitalar.}

O objetivo de levar aos hospitais algumas técnicas e serviços oriundos de hotéis tem a finalidade de minimizar o desconforto do cliente da saúde tornando sua estada mais agradável.

O cliente é um ser único que está num momento de vulnerabilidade, pois o seu bem maior - a vida, pode estar ameaçada. Esse cliente requer uma assistência segura e humanizada, além de competente no aspecto técnico-científico. Segundo o Manual do Ministério da Saúde (2000,), "humanizar é garantir à palavra a sua dignidade ética". Como o homem é um ser dotado de linguagem, essa linguagem precisa ser decodificada, ou seja, o outro deve reconhecer o seu significado No ambiente hospitalar, dor e sofrimento precisam ser reconhecidos e compreendidos 
de maneira humanizada, pois só assim o cliente percebe que todos no hospital têm um objetivo comum: atendê-lo e, sempre que possível encantá-lo. Para isso é necessário que a hospitalidade oferecida pelo hospital seja incondicional, isto, é seja compreendida como um conjunto de valores, modelos e ações que dizem respeito ao receber humano (CAMARGO, 2002).

O desenvolvimento científico e tecnológico tem trazido uma série de benefícios, sem dúvidas, mas tem como efeito adverso o incremento da desumanização, um hospital pode ser desumano no atendimento, por tratar as pessoas como simples objeto de intervenção técnica, sem serem ouvidos em suas angústias, temores e expectativas, ou sequer informados sobre o que está sendo feito com ela. A humanização no ambiente hospitalar nos mostra que somente ciência e tecnologia não bastam para atender bem o cliente. Quando apenas esses aspectos são considerados, o atendimento é desumano, pois não considera o sentimento das pessoas envolvidas. A hotelaria hospitalar tem importante papel a desempenhar para agregar valor à qualidade da assistência prestada ao cliente, não só de maneira direta, como também por meio das interfaces com os diversos serviços hospitalares.

\footnotetext{
O triunfo da hotelaria está na humanização do ambiente hospitalar: serviços eficientes que encantam, cores suaves, plantas e jardins bem cuidados e, principalmente pessoas entusiasmadas interagindo com os clientes da saúde, revelando de tal forma o segredo dessa nova proposta que é o sorriso sincero e permanente, marca registrada da satisfação e do amor pelo trabalho realizado. Os clientes da saúde (enfermos, familiares, acompanhantes, visitantes) sentem-se confiantes e motivados quando a solidariedade apresenta-se estampada nos semblantes de todos os envolvidos no seu atendimento (TARABOULSI, 2003, p. 40).
}

Percebemos que essa preocupação com a humanização do hospital envolve diferentes aspectos, que se referem não só aos cuidados de enfermagem prestados e ao tratamento de sua doença, mas também deve proporcionar um ambiente que contribua para que o cliente e sua família sintam-se seguros e confortáveis - a hotelaria hospitalar objetiva oferecer aos seus clientes condições de bem estar, segurança, conforto e qualidade no atendimento, tornando o ambiente hospitalar o mais próximo do ambiente familiar de seus clientes.

Neste contexto sociocultural do hospital, é importante considerar os vários serviços prestados pela hotelaria hospitalar, por intermédio de interações com outros 
serviços. A higiene e limpeza do ambiente e dos equipamentos, a qualidade do enxoval oferecido (lençóis, toalhas, camisolas (que deve ser colorido e de aspecto agradável, as refeições que devem atender aos aspectos curativos e gastronômicos, a recepção, que deve ser o cartão de visitas do hospital, acolhendo o cliente de maneira agradável. Mesmo o estacionamento do hospital precisa oferecer condições hospitaleiras: não se admite mais um estacionamento distante e inseguro.

Outros serviços prestados ao cliente dentro do ambiente hospitalar tais como lojas de conveniência, floricultura, espaços culturais para exposições e música, cyber café (local que funciona também com bar ou lanchonete, oferece aos seus clientes acesso à internet) para facilitar a comunicação em tempo real com o mundo, contribuem também para humanizar a assistência prestada ao cliente.

\subsection{Sinergia entre hotelaria hospitalar e psicologia hospitalar}

Temos visto que uma das vantagens da hotelaria hospitalar é o seu perfil eclético, ou seja, aquele que se harmoniza com diferentes correntes que existem. Como a hotelaria implica hospitalidade, a hotelaria hospitalar permite a interação entre todos os setores da instituição de saúde, com suas especialidades e equipes multiprofissionais, que, segundo Taraboulsi (2005) a torna um instrumento de apoio imprescindível para a recuperação psicológica e física dos clientes que ali se encontram. Ainda segundo o autor, essa parceria da hotelaria hospitalar e psicologia hospitalar representa um avanço enorme na qualidade da assistência psicológica, tendo em vista a sensação de confiança, acolhimento e segurança, oriunda dos serviços por elas prestados ser um ingrediente potencial na receptividade e na colaboração dos clientes da saúde, qualquer que seja o seu estado e ânimo, e auxilia o psicólogo tanto na prevenção como no tratamento.

Ao entrar no hospital, o doente passa por um processo de ruptura de vínculos, despersonalização, sensação de perda de controle de si próprio e medo do desconhecido. Isso tudo pode, ainda, gerar fantasias sobre a doença, seu tratamento e a recuperação. Além desses fatores, o psicológico necessita trabalhar as questões relacionadas à possibilidade de morte.

O hospital, para a maioria das pessoas, está associado a sofrimento, dor e perda. Neste sentido, as instituições modernas preocupam-se muito com a questão da hotelaria hospitalar, que tem como objetivo minimizar o impacto 
do ambiente físico em relação à hospitalização, tornando os clientes mais receptivos ao atendimento médico e psicológico (ISMAEL, 2005, p. 148).

A seguir são descritos alguns tipos de clientes, seguidos das dicas recomendadas pela hotelaria e a psicologia, que, segundo Taraboulsi (2005, p.252) para que os profissionais envolvidos tenham a consciência da importância do seu modo de agir, com discernimento e compreensão em todas as situações e circunstâncias:

Nervoso: ouvir com calma, ser tolerante e compreensivo, criar um clima agradável e, acima de tudo, evitar palavras e expressões de interpretação ambígua. É importante não usar o mesmo tom que o do cliente. Exige o dever da tolerância.

Meticuloso: é aquele que tem dificuldade para entender determinados assuntos. Requer paciência na exposição dos detalhes que ele considera importante e explicações simples, no ritmo dele, por meio de exemplos claros. Exige o dever da simplicidade e d paciência.

Tímido e inseguro: devemos, com cautela, dar-lhe segurança e confiança, sem pressioná-lo, e facilitar-lhe a compreensão dos fatos, tendo como referência a nossa própria experiência de timidez e insegurança em situações que nos causaram a mesma sensação. Exige o dever da empatia.

Desconfiado: fornecer respostas firmes e seguras, esclarecer todas as dúvidas apresentadas nos mínimos detalhes. Usar comparações que possam facilitar a compreensão a fim de levá-lo ao raciocínio lógico. Exige o dever da objetividade.

Irônico e presunçoso: aquele que sabe tudo, cita amizades influentes e tenta dominar a situação. A ele deve ser oferecido um tratamento simples e objetivo, respeitando sua maneira de ser, sem nenhuma expressão facial ou gesto que venha a transmitir reciprocidade de tratamento, pois este tipo de cliente não gosta de ver nos outros aquilo que é evidente nele. Exige o dever da perspicácia.

Agressivo: difere muito do cliente nervoso, cujo comportamento é circunstancia. É aquele que traz frustrações e culpa interior. Evitar argumentos que requerem explicações e culpa interior. Evitar argumentos que requerem explicações longas e desgastantes. Exige o dever da síntese.

Satisfeito e encantado: aquele que espera sempre um atendimento que lhe confirme a sensação de encantamento e satisfação. Atenção redobrada, solicitude e alegria são imprescindíveis para que ele mantenha as expectativas elevadas. É o tipo de cliente que deve ser reconquistado a cada dia, Capaz de compreender 
pequenos incidentes, mas, em caso de frustração forte, pode se transformar no mais cruel e impiedoso dos clientes: aquele que não volta mais. Exige o dever da continuidade.

Presume-se que a exposição dos perfis acima é fundamental para levar os profissionais de saúde, de todos os setores e categorias, a refletir sobre suas atitudes, pois o fato de se mostrarem capacitados a sentir a possibilidades de conflitos e evitá-los, já representa uma contribuição importante para o serviço visando propiciar humanização e qualidade no atendimento.

Segundo Ismael (2005) a psicologia hospitalar é uma área que existe há pelo menos trinta anos, mas só foi reconhecida como uma especialidade da psicologia em 2007. Por ser uma área nova, muitos hospitais não possuem psicólogos no seu corpo de funcionários. Em contrapartida, as instituições que já contam com o trabalho desses profissionais investem cada vez mais no trabalho, com o objetivo de melhorar e aprimorar seus serviços prestados aos clientes. Cabe ao psicólogo hospitalar prestar assistência aos doentes e familiares que adentram o hospital, tanto para o tratamento clínico como para o cirúrgico (ISMAEL, 2005).

O quadro de similaridades entre a psicologia hospitalar e a hotelaria hospitalar que, segundo Taraboulsi (2009), evidenciam o elo que a psicologia mantém com a hotelaria hospitalar. 


\subsubsection{Similaridades entre a psicologia hospitalar e a hotelaria hospitalar}

\begin{tabular}{|c|c|}
\hline ospitalar & lar \\
\hline $\begin{array}{l}\text { A psicologia hospitalar é o ramo da } \\
\text { psicologia que se diferencia dos demais } \\
\text { por oferecer, principalmente, } \\
\text { atendimento psicológico humanizado a } \\
\text { clientes de saúde hospitalizados e } \\
\text { submetidos a procedimentos médicos, } \\
\text { clínicos ou cirúrgicos. }\end{array}$ & $\begin{array}{l}\text { A hotelaria hospitalar é a arte de } \\
\text { oferecer serviços repletos de presteza, } \\
\text { alegria, dedicação e respeito, fatores } \\
\text { que geram a satisfação e o } \\
\text { encantamento do cliente de saúde e, } \\
\text { acima de tudo, que propiciam a } \\
\text { humanização do atendimento e do } \\
\text { ambiente hospitalar. }\end{array}$ \\
\hline $\begin{array}{l}\text { A psicologia hospitalar implica a arte de } \\
\text { ouvir e, sobretudo, o uso concreto da } \\
\text { palavra, elementos potenciais de } \\
\text { motivação e cura. }\end{array}$ & $\begin{array}{l}\text { A hotelaria hospitalar implica a arte de } \\
\text { ouvir e, sobretudo, o uso da palavra e do } \\
\text { sorriso sincero, elementos potenciais de } \\
\text { comunicação, } \quad \text { confiança } \\
\text { encantamento. }\end{array}$ \\
\hline $\begin{array}{l}\text { A psicologia hospitalar trata de clientes } \\
\text { de saúde cuja presença no ambiente } \\
\text { hospitalar é involuntária. }\end{array}$ & $\begin{array}{l}\text { A hotelaria hospitalar oferece serviços } \\
\text { eficientes a clientes de saúde cuja } \\
\text { hospedagem no ambiente hospitalar é } \\
\text { involuntário }\end{array}$ \\
\hline $\begin{array}{l}\text { Além do enfermo, a assistência } \\
\text { psicológica no ambiente hospitalar é } \\
\text { estendida necessariamente aos familiares, } \\
\text { com o objetivo de compreendê-los e dar- } \\
\text { lhes o suporte adequado para torná-los } \\
\text { importantes colaboradores. }\end{array}$ & $\begin{array}{l}\text { Além do enfermo, os serviços da } \\
\text { hotelaria hospitalar beneficiam } \\
\text { acompanhantes, visitantes e familiares, } \\
\text { transformando estes últimos em } \\
\text { importantes colaboradores. }\end{array}$ \\
\hline $\begin{array}{l}\text { A equipe multiprofissional, o médico, } \\
\text { essencialmente, tem na psicologia } \\
\text { hospitalar um valioso aliado na } \\
\text { preparação do cliente de saúde para o } \\
\text { tratamento clínico e cirúrgico. }\end{array}$ & $\begin{array}{l}\text { A equipe multiprofissional, em especial } \\
\text { médicos e psicólogos, tem na hotelaria } \\
\text { hospitalar um valioso aliado, capaz de } \\
\text { amenizar o impacto do ambiente } \\
\text { hospitalar, tornando a internação uma } \\
\text { hospedagem acolhedora } \\
\text { aconchegante. }\end{array}$ \\
\hline
\end{tabular}


Verificamos que a comparação do quadro mostra o grau de convergência entre a hotelaria hospitalar e a psicologia hospitalar. Tanto uma como a outra interagem com todos os serviços existentes na instituição de saúde, e a importância dessa inter-relação são instrumentos de motivação que objetivam a cura.

Ao comparar as duas colunas, percebemos que a primeira quebra a resistência ao ambiente hospitalar, transforma a hostilidade presumida em hospitalidade. É a mão amiga que recebe o enfermo e seus familiares e os conduz com alegria e eficiência até a assistência médica e psicológica.

Já a segunda coluna, na opinião de Taraboulsi (2009) quebra a resistência ao tratamento médico, ameniza a angústia e o medo; transforma silêncios em diálogos amigáveis, conflitos internos em reflexões positivas e resistência em colaboração espontânea. É o ombro amigo que ouve o apelo, sente a angústia, entende o grito, analisa a mensagem e responde com a ação adequada.

\subsection{Gastronomia hospitalar}

De acordo com Guimarães (2007), desde a antiguidade, a associação entre alimentação, dietética e saúde é descrita como recurso terapêutico. Os hospitais eram atendidos por leigos, irmãs de caridade; o risco em relação à alimentação era amenizado com alimentos chamados de dieta (com pouco sal, sem gordura, sem tempero), daí o conceito de "comida de hospital" que se reflete até os nossos dias. Atualmente a expressão "comida de hospital", habitualmente associada à imagem negativa da área de nutrição hospitalar, tem se tornado cada vez menos freqüente. Com o surgimento e a evolução dos hospitais, apresentaram-se avanços clínicos, aliados às ações de hospitalidade e hotelaria para a promoção da qualidade de vida dos clientes.

Acreditamos que o setor de nutrição e dietética focou sua atenção na recuperação do paciente e se esqueceu do glamour da gastronomia, por isso a comida hospitalar ganhou fama de comida sem tempero, sem cor e criatividade sendo conhecida como comida ruim e sem graça; três motivos colaboram para essa imagem:

a) Devido ao consumo de remédios e drogas o paciente acaba perdendo e alternando seu apetite, olfato e paladar;

b) O estresse da internação também influencia no seu humor e apetite; 
c) Existe ainda a questão de dietas especiais tornando muitas vezes em tempero e dietas restritas a líquidos ou alimentos de forma pastosa.

Porém há pacientes que podem alimentar-se de qualquer refeição (dieta livre). A gastronomia hospitalar surge com o intuito de confrontar a adequação da dieta a patologia do paciente levando em conta hábitos regionais e com ingredientes, técnicas dietéticas eficazes.

O investimento em atendimento cresceu muito nos últimos anos, tornando-se um diferencial de mercado e fazendo com que o usuário se sinta cada vez mais cliente e menos paciente. Os profissionais de nutrição têm investido bastante para mudar o velho conceito de que comida de hospital é insípida. A nova tendência da gastronomia oferece um atendimento individualizado personalizado como sendo o grande diferencial para o alcance do conceito de gastronomia hospitalar, respeitando as preferências e aversões alimentares, bem como os hábitos regionais, sem, contudo, perder o equilíbrio nutricional. Dentre os diversos aspectos envolvidos na gastronomia hospitalar, são apontados que os cardápios e dietas hospitalares devem respeitar:

- Os hábitos alimentares do paciente (pontos de cocção, temperos, consistência, apresentação, variedade);

- A necessidade do paciente em termos de quantidade de sua alimentação;

- O direito de escolha (ou alternativa de opção) do paciente;

- O direito do paciente ao diálogo com o responsável pela administração do serviço;

- O direito do paciente à informação relativa à alimentação (dieta) que lhe é servida.

Atualmente, a visão de dieta hospitalar está sendo ampliada e adaptada às tendências inovadoras da gastronomia no mercado globalizado de alimentação e nutrição, é o desafio para integrar as Unidades de Nutrição e Dietéticas a um sistema de hotelaria aprimorado.

Gastronomia hospitalar é a arte de conciliar a prescrição dietética e as restrições alimentares de clientes à elaboração de refeições saudáveis e nutritivas, atrativas e saborosas, a fim de promover a associação de objetivos dietéticos, clínicos e sensoriais e promover nutrição com prazer (GUIMARÃES, 2007). 
Hoje há uma grande preocupação em se agregar prazer aos pratos produzidos. Prazer voltado para a apresentação, para o sabor, ao atendimento das preferências do paciente e de seus acompanhantes. Razões para essa mudança não faltam. Duas delas podem ser resumidas nas palavras humanização e competitividade: o respeito que o paciente merece inclui fornecer alimentos adequados e saborosos e isso faz com que uma boa imagem do hospital possa ser difundida pelas características da alimentação que oferece.

Os fatores sensoriais são representados pelos órgãos dos sentidos; as características sensoriais dos alimentos são mensuradas, avaliadas e interpretadas através do olfato, visão, paladar, tato e audição. Na opinião de Guimarães (2007), no meio hospitalar, a associação desses fatores (nutrição versus comportamento), atinge maior grau de complexidade, uma vez que os indivíduos, mesmo que temporariamente, são deslocados de seu convívio social. A mudança de ambiente e a alteração do significado simbólico dos alimentos passam a ser limitantes do desenvolvimento normal do apetite.

Verifica-se que os desafios da gastronomia nas dietas hospitalares não são poucos. Em diferentes aspectos vão desde a identificação precisa de necessidades e expectativas dos clientes, até a tradução mais fidedigna em produtos saudáveis, nutritivos, atrativos, gostosos e principalmente que colaborem para a manutenção e recuperação de estado nutricional.

Guimarães (2007) destaca que o nutricionista não pode mais assistir passivamente as solicitações diversificadas, devendo agir com ciência, saber e criatividade para unir objetivos dietéticos, clínicos e sensoriais. Verifica-se que a associação entre alimentação, dietética e saúde como recurso terapêutico, é descrita desde a antiguidade; aplicada de maneira empírica e posteriormente, estudada e comprovada. Desde o surgimento dos hospitais, até a sua evolução, apresentam-se avanços em tendência terapêuticas, aliados às ações de hospitalidade e hotelaria, para a promoção da qualidade de vida e conforto dos clientes. 


\subsection{Gestão de informação hospitalar}

Um sistema de informação hospitalar pode ser descrito como sendo um sistema desenhado para auxiliar na gestão de toda informação clínica e administrativa da instituição, e melhorar a qualidade da prestação de cuidados de saúde interagindo com outros sistemas já existentes (MORAES 2004)

Algumas informações importantes do paciente ainda estão em papel, tais como termo de responsabilidade e consentimento. O sistema de gestão da informação é uma ferramenta importante e dinâmica para a realidade que vêm substituir os sistemas manuais e eletromecânicos e dar agilidade e segurança aos processos operacionais e administrativos de controle.

Buscar meios e tecnologia para permitir ao diretor do hospital ter uma ampla e imediata visão de todo o complexo (meio) que representa um hospital. A informatização de todos os setores é fundamental, o dirigente necessita ter em mãos instrumentos de fácil manuseio, precisos e atualizados, que lhe permitam, com o pouco tempo livre de que dispõe, manter-se atualizado a respeito dos acontecimentos de todos os setores.

\footnotetext{
"A complexidade de um hospital é tamanha que se torna muito difícil controlar todos os segmentos sem o auxilia da informatização... Para os hospitais já existem, no mercado, sistemas semelhantes aos da hotelaria, porém voltados exclusivamente para a realidade dos hospitais. Alguns desses programas são bem amplos e completos, contemplando diversos controles, nos mais diversos setores de um hospital" (MORAES, 2004, p.128).
}

De acordo com Taraboulsi (2009), o objetivo do sistema de informação de gestão hospitalar é otimizar todos os processos desempenhados pela instituição de saúde, o que representa ganho na qualidade dos serviços hospitalares, maior visão estratégica e maior eficiência tática e operacional e, essencialmente adequado apoio à gestão da relação com os clientes em todos os pontos de negócio.

Nesta abordagem sobre sistemas de gestão, existe uma inter-relação entre inovações tecnológicas e inovações administrativas. O mercado, através do setor de tecnologia, disponibiliza novos sistemas de gestão que as instituições de saúde adotam para estar na vanguarda das inovações ou, no mínimo, permanecerem competitivas e fazer frente à concorrência. 
Devido às mudanças frenéticas da realidade atual, surgem novas necessidades que levam essas mesmas instituições a exercer pressão sobre o setor de Tecnologia da Informação e este, por sua vez, desenvolve novos softwares para que a demanda e as necessidades do mercado sejam devidamente atendidas. Por exemplo, é o caso da introdução da hotelaria no ambiente hospitalar, que exige um sistema de gestão eficaz e flexível para que a implementação dos serviços de hotelaria venha a guardar uma relação de coerência para com o ramo de atividade ao qual os hospitais pertencem" ( TARABOULSI, 2009, p.168).

Segundo afirmação de Taraboulsi (2009), a solução através de sistemas de gestão hospitalar contempla praticamente todas as áreas assistenciais e administrativas, possibilitando a integração, em tempo real, de todas as informações da instituição de saúde. Esta solução abrange: pré-internações, agendamento de exames e consultas, internações e altas, informações sobre coberturas de planos de saúde, emissão de guias, controle do pronto-socorro, resultado de exames, laudos, imagens, prescrição eletrônica, protocolos clínicos, enfermagem, gerenciamento de leitos/vagas, programação cirúrgicas, prontuário eletrônico, nutrição, psicologia, fisioterapia, laboratório, almoxarifado,compras, farmácia, fornecimento de medicamentos e materiais, faturamento, financeiro, controladoria, marketing, comercial, recursos humanos, serviços de hotelaria hospitalar e demais departamentos.

Dentro do novo contexto que o mundo globalizado apresenta, estes sistemas de gestão fornecidos pela Tecnologia da Informação são um instrumento imprescindível para a instituição de saúde, pois oferecem possibilidade de permanente atualização e integração do negócio e oportunidades de estar entre os melhores do setor, visto que potencializa os processos de tratamento, propagação e transferência de informações, agregam valor aos serviços e tornam a tomada de decisão mais ágil, eficaz e coerente com as condições do presente e as previsões do futuro.

\subsection{Setores e departamentos dentro de hospitais}

Os departamentos e cargos citados a seguir, são considerados os básicos para a execução dos serviços de hotelaria hospitalar, no entanto, dependendo da categoria e porte do hospital outras funções podem ser criadas e adaptadas como coordenador de marketing, departamento de eventos, capitão-porteiro, entre outros. 
Outro grupo de funcionários ou voluntários que exercem papel importante dentro do hospitalo são os que, através do riso e da alegria, buscam minimizar o sofrimento do paciente.

\subsubsection{Lavanderia hospitalar}

Nos atuais serviços de saúde, os bons cuidados do paciente e os melhores resultados são vistos como "produto" das ações e interações de todas as pessoas envolvidas no processo.

A lavanderia hospitalar, segundo o Ministério da Saúde - Manual de Lavanderia hospitalar, 1986, é um dos serviços de apoio ao atendimento dos pacientes e compete transformar todas as roupas sujas e contaminada em roupas limpas, ou seja, coletam, pesam, separam, processam, confeccionam, reparam e distribuem roupas em perfeitas condições de higiene, conservação e limpeza para todas as unidades do hospital, a fim de controlar infecções hospitalares e proporcionar conforto e segurança satisfatoriamente tanto aos funcionários quanto aos pacientes. Já Castro (2001), afirma que o serviço de lavanderia, rouparia e costura de um hospital é de suma importância para o bom funcionamento do hospital, visto que a eficiência de seu funcionamento contribuirá para a eficiência do hospital.

Obedecendo ao segmento de uma série de instrumentos normativos elaborados pelo Ministério da Saúde, que ressalta a importância da lavanderia dentro do complexo hospitalar, pois da eficácia de seu funcionamento depende a eficiência do hospital, refletindo-se especialmente nos seguintes aspectos:

- Controle de infecções;

- Recuperação, conforto e segurança do paciente;

- Facilidade, segurança e conforto da equipe de trabalho;

- Racionalização de tempo e material;

- Redução dos custos operacionais.

Apesar da evidência de sua importância, na maioria dos hospitais, o serviço de lavanderia não recebia a atenção devida, sendo muitas vezes confiada a trabalhadores sem os devidos conhecimentos, seja pela carência de profissionais 
com formação específica na área, ou mesmo pelo descaso por parte dos dirigentes do hospital, com relação ao devido setor (MEZZOMO, 1984).

As roupas hospitalares diferem daquelas utilizadas em outros tipos de instituições ou residências visto que alguns itens apresentam-se contaminados com sangue, secreções ou excreções de pacientes em maior quantidade de contaminação e volume de roupa, mas não diferentemente das sujidades encontradas nas roupas da comunidade em geral.

É importante observar que além de higienizar, a lavagem também deve ser realizada de forma a garantir a manutenção das características físicas das roupas e ainda assegurar a eliminação de substâncias irritantes ou alergênicas, incluindo os sabões, amaciantes desinfetantes e removedores de manchas utilizados durante o processo.

Uma lavanderia hospitalar precisa utilizar produtos de composição confiável e máquinas condizentes com o porte e o tipo de atendimento realizado no hospital, deve possuir áreas físicas adequada e manter programas de educação continuada para seus funcionários (MEZZOMO, 1980).

De acordo com a Agência Nacional de Vigilância Sanitária (2007), as atividades realizadas pela lavanderia são citadas seguindo a descrição: retirada de roupa suja da unidade geradora e o seu acondicionamento; coleta e transporte de roupa suja até à unidade de processamento; recebimento, pesagem, separação e classificação da roupa suja; processo de lavagem de roupa suja; centrifugação; secagem,calandragem ou prensagem ou passadoria da roupa limpa; separação, dobra, embalagem da roupa limpa e armazenamento, transporte e distribuição da roupa limpa.

\subsubsection{Operacionalização da lavanderia hospitalar}

De acordo com o Manual de Lavanderia Hospitalar, a operacionalização eficiente da lavanderia depende de alguns fatores precedentes desta fase como por exemplo uma boa organização, uma chefia competente, um programa efetivo de treinamento em serviço e a adoção de sistemas adequados de incentivos. Ainda Segundo a Manual sem a harmonia desses quatros fatores, indispensáveis ao controle de mão-de-obra, a produção será ineficiente mesmo dispondo da mais moderna tecnologia. A operacionalização abrange todo o circuito da roupa, desde a 
sua utilização nas diversas unidades do hospital, passando pela coleta da roupa suja nessas unidades, até sua redistribuição após o devido processamento.

Para Konkenwicz (2004), a organização do trabalho da lavanderia deve começar considerando a área física. Onde se deve atentar para que o processamento da roupa não seja realizado em um só ambiente da lavanderia, pois - manejo da roupa suja favorece à recontaminação da roupa limpa com microorganismos lançados no ar. Para evitar esse tipo de risco ela apresenta a seguinte rotina de recolhimento e transporte da roupa usada no hospital:

- Roupa suja deve ser manuseada e sacudida o menos possível, devendo ser transportada ao serviço de lavanderia em sacos resistentes e bem vedados.

- As roupas sujas devem ser colocadas nas unidades e enfermarias em sacos de pano de "hamper" e alojadas em sala específicas para materiais sujos.

- Roupas com sujidade pesada, ou seja, muito sujas com matérias orgânica devem ser acondicionadas com sacos plásticos dentro de sacos de pano de "hamper", para evitar extravasamento e risco de contaminação ambiental.

- Os sacos de "hamper" contendo roupa suja devem recolhidos pelo pessoal da lavanderia, no mínimo 3 vezes ao dia, para evitar seu acúmulo nas unidades.

- O transporte de roupa suja deve ser feito em carros grandes com rodas, dentro dos setores do hospital.

- Os carros de transporte de roupa suja devem ser devidamente identificados para diferenciá-los dos carros usados para o transporte de roupa limpa, a fim de se evitar uma troca acidental.

- Todos os locais e carros utilizados para o recolhimento e transporte da roupa devem ser diariamente lavados com água e sabão.

- Preferencialmente, o fluxo de transporte da roupa suja não deve coincidir com o fluxo da roupa limpa.

Diante do exposto, entendemos que a fase de organização da lavanderia pressupõe, sempre, um planejamento anterior. Ao se organizar uma lavanderia hospitalar, todo o seu funcionamento deve estar descrito em manual de orientação, contendo a especificação de cada atividade, a estrutura hierárquica, normas e rotinas mostrando claramente a organização e execução do trabalho. 


\subsubsection{Departamento de Recepção e hospedagem}

O Unidade de Recepção é responsável pela orientação e coordenação das atividades operacionais da recepção, hospedagem, reservas, mensageria, telefonia, conciergerie (portaria social) e Pronto Socorro, , de acordo com os princípios da hotelaria hospitalar adaptada e proporcionando aos clientes de saúde serviços de qualidade, nos quais a eficiência e a cortesia se destacam em todas as etapas do atendimento (TARABOULSI,2009).

A recepção é o local que, na hotelaria é considerado o coração do hotel, e, na opinião de Moraes (2004), em um hospital o bom funcionamento da recepção poderá ser fator importante e decisivo para o sucesso do restabelecimento do paciente. Assim que o paciente chega a uma instituição de saúde, a estrutura física naquele momento deve estabelecer que suas expectativas futuras sejam positivas.

Segundo Guimarães (2007), a recepção da Unidade de Internação terá grande influência sobre este primeiro olhar do paciente. Enquanto o cliente aguarda o processo de internação, é importante que o espaço deixe transparecer que o hospital é organizado, limpo, colorido, tranqüilo, amplo e aconchegante.

A Unidade de Recepção reporta-se diretamente ao gerente de hotelaria através do gerente de recepção e hospedagem que tem a responsabilidade de comandar uma estrutura operacional buscando harmonizar os serviços de hotelaria de recepção e hospedagem com os serviços médico/hospitalares, desde a chegada do cliente de saúde até a sua alta.

Tem relação funcional com a governança, em que a interação constante com a governanta do hospital é imprescindível para que os serviços de limpeza, higiene, lavanderia e liberação de unidades de internações possam ser bem executados dentro de uma programação definida, facilitando as internações e as altas dando continuidade aos serviços de hotelaria oferecidos ao cliente de saúde. (TARABOULSI, 2009).

Segundo Moraes (2004), o recepcionista do setor de internação e altas de um hospital tem um cargo correspondente ao de um recepcionista de um hotel com algumas características específicas: o conhecimento de detalhes referentes à saúde e à atividade intrínseca de um hospital, que um recepcionista de um hotel não necessita saber; entretanto, a base será a mesma em se tratando de cortesia, simpatia, empatia, sorriso fácil, franqueza, responsabilidade, agilidade, iniciativa, 
atenção, dinamismo, polidez e, principalmente, conhecimento técnico e qualidade no atendimento.

\subsubsection{Atribuições e responsabilidades.}

As atividades básicas do gerente de recepção e hospedagem são muitas e demandam percepção aguda e supervisão constante, principalmente na fase inicial de implantação da hotelaria hospitalar. Eis algumas das principais atribuições (MORAES, 2004, p.60).

- acompanhar, junto à área de recursos humanos, o processo de seleção, de treinamento e de integração de pessoal destinado à recepção;

- conhecer com profundidade o trabalho de todos os seus subordinados e os procedimentos de outros setores ligados à recepção;

- controlar e organizar com a governança, a copa e outros setores, quando necessário, a chegada e a estadia de pacientes;

- criar um harmonioso ambiente de trabalho para todos os empregados do departamento de recepção e hospedagem, ressaltando ao grupo a importância da interação com os demais empregados da instituição de saúde;

- estar atento ao que ocorre no hospital. Acompanhar as tendências do mercado e a evolução dos serviços de hotelaria hospitalar em outras instituições;

- conscientizar os empregados do departamento de recepção e hospedagem dos objetivos de hotelaria e sua importância no apoio aos serviços médicohospitalares;

- avaliar regularmente o desempenho de todos os empregados e desenvolver ao máximo o potencial de cada um, orientando e determinando o pontos a serem corrigidos, e recomendar aumento de salários e promoção ao gerente de hotelaria quando apropriado; 


\subsubsection{Departamento de Segurança e Portaria}

Na hotelaria clássica, o concierge ou porteiro social é o colaborador que mantém maior contato com o hóspede durante sua estada no hotel. Na hotelaria hospitalar, o concierge ou porteiro social exercerá importante função uma vez que, igualmente como nos hotéis, exercerá sua atividade diretamente no atendimento a clientes da saúde, pacientes, acompanhantes, e visitantes em geral.

O concierge ou porteiro social é o encarregado de coordenar os mensageiros, o capitão-porteiro, os manobristas e os assistentes de limpeza e higiene que atuam na entrada do hospital, no hall, nos corredores de acesso e no portal de entrada.

\footnotetext{
O cliente necessita sentir que a instituição hospitalar cuidará de sua segurança física em todas as dimensões. O serviço de segurança patrimonial será o responsável pela manutenção da integridade das instalações e de seus usuários (GUIMARÃES,2007, p.36).
}

De acordo com Moraes (2004), o profissional indicado para exercer a função de concierge deverá ter inúmeros requisitos, entre os quais, podem ser destacados os seguintes:

- Facilidade de expressão e comunicação;

- Simpatia;

- Empatia;

- Dinamismo e cortesia;

- Agilidade mental;

- Objetividade;

- Responsabilidade;

- Profundo conhecimento de sua atividade.

$\mathrm{O}$ atendimento prestado por todos os serviços de apoio deve permitir que o "ser humano" sinta-se respeitado em suas principais necessidades, nesse período crítico de vida. 


\subsubsection{Departamento de A \& B (Alimentos e Bebidas)}

Em primeiro lugar, consideramos de suma importância distinguir a área de nutrição, coordenada por uma nutricionista-chefe que trabalha com critérios técnicos peculiares (dietas) e presta serviço exclusivamente às pessoas enfermas, do departamento de alimentos e bebidas, que tem um público-alvo os familiares, os acompanhantes, os visitantes, os clientes da saúde (a pessoas enferma) que não tem restrições alimentares e todas as pessoas que freqüentam a instituição de saúde.

O gerente de alimentos e bebidas na hotelaria hospitalar é uma inovação. Sua atuação em hospitais difere um pouco da atividade desenvolvida em grandes hotéis. Nos hospitais, o gerente de A\&B (alimentos e bebidas) comandará uma estrutura física e operacional adaptada às necessidades hospitalares, pois, muitas vezes, não é o cliente quem escolhe sua própria alimentação, mas deve seguir a dieta recomendada para o seu caso clínico. Na hotelaria hospitalar, o gerente de A\&B atua em conjunto com o Departamento de Nutrição, que é responsável pelas dietas especiais, e o entrosamento entre o gerente de A\&B e a chefia de nutrição pode trazer grandes benefícios, acoplando qualidade e inovação aos serviços e alimentos colocados à disposição dos clientes de saúde, médicos, público interno e externo (TARABOULSI, 2009).

De acordo com Moraes (2004), o gerente de A\&B é responsável pelo planejamento, pela organização, pelo controle e pela supervisão-geral das atividades operacionais, técnicas e administrativas dos setores de alimentação e bebidas, tais como restaurante, bar, copa, cozinha e setores de apoio, inclusive, os contratados e terceirizados.

Para exercer a função gerencial, o profissional deverá ter pré-requisitos e atender as exigências que variam em cada estabelecimento. Deve estar sempre em contato com o departamento de eventos cuja estrutura organizacional necessita muito dos serviços de alimentos e bebidas. Elencam-se, a seguir, algumas exigências e o perfil básico necessário a um gerente de alimentos e bebidas.

- acompanhar as condições e tendências do mercado colaborando no planejamento de vendas e marketing;

- acompanhar as tendências e as ofertas do mercado de materiais e produtos sujeitos a variações sazonais; 
- acompanhar e analisar a evolução dos custos e preços de pratos;

- acompanhar e sugerir níveis de estoque máximos e mínimos dos materiais, bem como as condições de armazenagem e transporte;

- avaliar com regularidade a performance do pessoal do departamento, corrigindo eventuais falhas e alterando procedimentos quando for necessário;

- estabelecer e fiscalizar a aplicação de normas disciplinares relacionadas com a conduta e a higiene pessoais dos funcionários;

- manter-se em permanente contato e interagir com o Departamento de Nutrição do hospital para elaboração de normas e operações com vistas a eliminar qualquer possibilidade de contaminação alimentar.

- atuar com o coordenador do departamento de eventos na captação de novos eventos e supervisionar os eventos que estão sendo realizados nas salas de reuniões do hospital, especialmente nos intervalos do coffee-break,, almoço e jantar, quando for o caso.

De acordo com Taraboulsi (2009), "cada gerente tem um perfil próprio que o distingue dos demais. Sua maneira de ser de conduzir sua área determinam o seu estilo". Entretanto a conduta e o visual do gerente de A\&B são fatores importantes para sua imagem dentro da instituição,

\subsubsection{Departamento de Lazer e Entretenimento}

A vida moderna tem imposto um ritmo frenético, é incontestável a importância do lazer em nosso dia-a-dia como válvula de escape, até porque, através de sua prática podemos liberar energias negativas acumuladas e refazer-nos do desgaste, oriundo da devastação psíquica devido a loucura diária da vida urbana na qual estamos inseridos.

No ambiente de trabalho, é necessário lançar mão de brincadeiras como instrumento para aliviar tensões que surgem e até para desenvolver a criatividade.

O líder nato sabe ser bem humorado, sabe brincar; em momentos tensos, é aquele que conta uma piada para descontrair o grupo, aliviar a tensão e levantar o astral geral. O humor deve ser uma bandeira institucional, defendida por todos médicos, enfermeiros, gerentes, profissionais da área (TARABOULSI, 2005, p. 256). 
Há alguns anos, admitir a inter-relação entre o humor e a boa saúde era uma utopia. No entanto, várias pesquisas científicas destacam a importância do bom humor na prevenção de doenças, na recuperação de moléstias graves, na motivação no ambiente de trabalho e, sobretudo, na qualidade de vida e da saúde.

Na opinião de Taraboulsi (2009), a disponibilidade de uma estrutura de lazer e bem-estar representa o grau de engajamento dos hospitais no tratamento dos cliente de saúde, primando pelo aspecto social e seu impacto na recuperação.

Para isso, é imprescindível que os hospitais implementem ações e investimentos, proporcionando opções de lazer, que, na essência , guardam relação muito positiva de custo /benefício voltado somente para o bem-estar dos clientes de saúde, sem nenhuma pretensão de lucro (TARABOULSI, 2009, p. 126).

O departamento de lazer e de bem-estar é responsável pela promoção de atividades de lazer: ginástica, aulas de artes, música, educação física, jogos e brincadeiras, peças teatrais, brinquedoteca, cinema, recitais de música nas áreas sociais, salas de leitura, biblioteca. Esse departamento tem como principal propósito promover a humanização do atendimento ao cliente de saúde.

Uma realidade cada vez comum em muitos hospitais é possuir uma brinquedoteca, e melhor ainda, possuir um profissional para cuidar dela, ou capacitar os profissionais da saúde para melhor utilizá-la. A criança não sabe ou não entende completamente o que está acontecendo com o seu corpo ou à sua volta. Colocar brinquedotecas dentro de um hospital permite que a criança volte a ser criança, mesmo em breves momentos de sua internação (GODOI, 2004).

Outro grupo de funcionários ou voluntários que exercem papel importante dentro dos hospitais, que no Brasil já existem são conhecidos como os "Doutores da Alegria", um grupo formado por atores que visitam os hospitais, transformando o dia-a-dia de pacientes pediátricos em momentos de alegria e felicidade que, através do riso e da alegria, buscam minimizar o sofrimento do paciente, principalmente as crianças.

Alguns hospitais têm projetos de recreação, utilizando-se de profissionais que se vestem como médicos, porém fantasiam-se com nariz, adornos e sapatos de palhaço visando ao entretenimento, principalmente dos pacientes de andares pediátricos (...) é grande a importância desse trabalho para a mudança de humor do paciente e, conseqüentemente, facilidade no tratamento interpessoal com a equipe médica e hotelaria do hospital (BOEGER, 2003, p. 39). 
Esses profissionais que promovem a risoterapia contribuirão, juntamente com os demais funcionários da saúde e da hotelaria hospitalar, na recuperação física e mental dos pacientes. A risoterapia é uma terapia bilateral, conforme Lambert (1999, p. 22) afirma, envolver a comunicação consigo mesmo e com o outro. É benéfica para quem dá e para quem recebe. Afirma ainda que a expressão da alegria e do bom humor tem um caráter terapêutico, despertando inicialmente em nós e depois nos outros, principalmente nas pessoas necessitadas de uma injeção de otimismo, o bem-estar, o bom humor e a saúde.

\subsubsection{Departamento de Governança}

A função de governanta era restrita a hotéis e atualmente tem se inserido a hospitais, devido à necessidade de um profissional especializado para cuidar da hospedagem e serviços de quarto, que são muitos semelhantes. Esses profissionais não apenas cuidam dos apartamentos como também podem realizar diferentes formas de arrumação dos apartamentos, trazendo da hotelaria clássica os modelos de arrumação que "venham a melhorar e valorizar a estada do paciente no quarto. Em alguns hospitais os lençóis deixaram de ser brancos e foram substituídos por lençóis com temas florais" (GODOI, 2004).

O setor de governança, assim como no hotel, abrange a maior área física do empreendimento: apartamentos, corredores, área social e algumas áreas operacionais de andares, lavanderia, higiene e limpeza. De acordo com Boeger $(2003$,$) centralizar todas essas operações sob responsabilidade de uma governanta$ também é bastante interessante, pois otimiza o tempo da equipe de enfermagem em priorizar a área assistencial. A camareira, assim como no hotel, é responsável pela arrumação e higienização das unidades de internação e das área físicas hospitalares, sendo que no hospital a camareira exerce suas funções em contato direto com o paciente, pois este permanece na cama a maior parte do tempo. 


\subsection{Quebrando paradigmas}

Sabemos o quanto um cliente insatisfeito faz referências negativas ao serviço mal prestado. Fidelizar é necessário em qualquer negócio, mas nos ambientes hospitalares temos diferenciações. Alguns tratamentos serão finalizados, outros não, porém todos os momentos em que os clientes da saúde permanecem dentro da instituição serão lembrados. Daí novamente a importância da hotelaria hospitalar e quebrar este paradigma.

Os hospitais que não se adequarem a este novo conceito estarão destinados ao fracasso e muitas vezes a extinção. Os clientes insatisfeitos migrarão para outros e nestes permanecerão desde que ofereçam diferenciais. Os hospitais sem esta visão ficarão obsoletos e deverão limitar-se em receber os clientes simplesmente encaminhados para lá, pois, se puderem escolher, não iriam.

\subsection{Hotelaria Hospitalar: Investir para sobreviver}

O conceito de hospitalidade hoje é bastante conhecido pelas instituições hospitalares, mas ainda não geram muitos investimentos, principalmente pelas instituições que trabalham com o Sistema único de Saúde (SUS). É muito simples entender os porquês da falta de investimento. A ausência de recursos financeiros é ainda com certeza o que mais contribui para que não tenhamos o setor de hospitalidade bem desenvolvido, entretanto, pode-se perceber que a falta de conhecimento e resistências às mudanças, também são responsáveis.

Cândido et al (2004) afirmam que há poucos anos, as organizações hospitalares começaram a perceber que seus clientes e pacientes tinham as mesmas necessidades que um consumidor comum, e que a organização não estava correspondendo à satisfação dessas necessidades. Ainda conforme Cândido; Moraes; Viera (2004,), estes pacientes necessitam de tecnologia, segurança, conforto, bom atendimento e um ambiente que proporcionasse a sensação de estar em casa e/ou um hotel. 
É necessário entender que a hotelaria hospitalar também traz recursos, ou seja, ela também gera lucro e é um centro de negócios. Primeiramente é necessário encontrar o equilíbrio, estabilizar o setor, mantendo controle efetivo das despesas e custos. Isto parece lógico, mas como muitos hospitais acreditam que isto não é possível ou não vêem este serviço como um centro de negócios, então não buscam este equilíbrio e daí através do prejuízo buscam justificar o não investimento. www.abifcc.org.br/noti10012006 (acessado em 15.03.10).

Nesse sentido, é preciso acreditar que a hotelaria gera receita e que para se obter retorno neste negócio é preciso investir. O que deve diferenciar neste ramo, como já vimos, é que o investimento não é apenas injetar dinheiro, é preciso acreditar em políticas de qualidade, excelência nos serviços prestados e trazer diferenças nessas ofertas, almejar uma equipe bem treinada, humanização, tornar a missão e visão da instituição comum a todos.

Muitas instituições de saúde estão adaptando seus serviços e instalações incorporando a hotelaria no seu processo de gestão, inserindo no ambiente hospitalar profissionais da arquitetura, turismo, hotelaria, gastronomia entre outras áreas e profissões atingindo-se resultados até então desconhecidos.

De acordo com a Organização Pan-Americana da Saúde - OPAS (2004), na mudança institucional, são conjugados valores, pessoas, cultura e capacidade gerencial, recebe-se a influência de condicionantes internas e externas; encaram-se resistências e superam-se obstáculos. Frente a tal complexidade, para definir o hospital do amanhã é preciso:

- $\quad$ articular um processo permanente de escuta (informação) e reflexão;

- formular uma proposta estratégica compartilhada (sentido ou razão de ser);

- manter uma liderança que leve a mudança (gerência);

- elaborar um plano compartilhado (participação organizada e responsável);

- assumir uma nova posição na organização para aprender a mudar ou aprender a aprender (cultura de aprendizado institucional).

As mudanças podem ser simples e não utilizar muitos recursos. Acreditamos que a principal alteração é a mudança de filosofia e de atitudes. Elas estão num atendimento humano e eficiente, na cordialidade e na empatia. Algumas mudanças buscam a quebra de paradigmas, como utilizar novas cores derrubando o conceito de que hospital apenas usa-se branco, som ambiente, salas de espera, lojas e serviços de hotelaria clássica de governança, lazer, recreação e alimentação. 
Os hospitais que desejam implantar a hotelaria hospitalar devem adequar a sua estrutura física para melhor atender as necessidades dos clientes. De acordo com Boeger (2003) o planejamento arquitetônico dos hospitais é uma tendência forte e irreversível, a hotelaria deve estar incorporada aos serviços hospitalares, mas também muito pode contribuir para o desenvolvimento estético do hospital .

Percebe-se que as instituições de saúde desejam perder a imagem de hospital e se parecer, cada vez mais, com um empreendimento hoteleiro. Essas mudanças podem se realizar principalmente, nas unidades de internação; nas salas de espera; na recepção; e na área de lazer infantil.

Os hospitais que investem neste novo modelo estão destinados ao sucesso e serão referência. "Toda tendência é uma oportunidade". A cada dia ela irá destinar os hospitais que ainda não a praticam a se adaptarem. Acreditamos que não é uma questão para ser aceita, mas, sim, necessária para sua sobrevivência. Esta tendência é possível para qualquer hospital, entretanto os particulares trazem maiores facilidades. 


\section{METODOLOGIA}

Metodologia é um conjunto de instrumentos utilizados na investigação, com a finalidade de encontrar o caminho para analisar de forma comprobatória a contribuição dos serviços de hotelaria hospitalar para os clientes da saúde em níveis de qualidade e como uma ferramenta de humanização e marketing.

Para a elaboração desse trabalho foram utilizadas como metodologia, duas formas de pesquisa: o de caráter bibliográfico (consulta a livros, revistas e artigos; à internet; ao Manual de humanização do Ministério da Saúde; entre outros) para dar embasamento teórico necessário demonstrando a ênfase no tema proposto; e a observação, buscando no método dedutivo que, segundo Vergara (2000), "constitui a base da pesquisa científica" A pesquisa foi realizada nos meses de maio à dezembro de 2009.

\subsection{Tipo de pesquisa}

Foi realizada uma pesquisa qualitativa e descritiva, junto a estudiosos e pesquisadores do tema, com a finalidade de coletar dados e informações. A técnica empregada foi de pesquisa bibliográfica. A intenção foi relatar, de forma sucinta e comprobatória, como os serviços de uma hotelaria hospitalar, em níveis de qualidade, agregam valor à hospitalidade, dando ênfase nos conceitos e na importância dos serviços para a humanização, para o bom atendimento e a satisfação do cliente da saúde.

Para a elaboração desse trabalho, desde o início do Curso foram empreendidas observações referentes à problemática em estudo. Além disso, também foram utilizados os conhecimentos adquiridos ao longo de anos de trabalho e convivência em uma instituição de saúde pública.

\subsection{Método utilizado}

O método escolhido foi o fenomenológico que, segundo Bello (2006), é uma reflexão sobre um fenômeno ou sobre aquilo que se mostra.

Para Edmund Husserl, a fenomenologia é uma ciência que busca a compreensão da essência que procede por descrição e não por dedução. A 
fenomenologia se ocupa da análise e interpretação dos fenômenos, mas com uma atividade diferente das ciências empíricas e exatas (TRIVINOS, 2002,p.43).

Considerando que a pesquisa é um processo de construção do conhecimento que tem como metas principais gerar conhecimento e/ou corroborar ou refutar algum conhecimento pré-existente. É um processo de aprendizagem tanto do indivíduo que a realiza quanto da sociedade na qual esta se desenvolve.

O fato de atuar na área da saúde há 18 anos, nos leva à percepção de uma ausência de ações humanas na área hospitalar e a carência de mudança na gestão institucional que conjuguem valores, pessoas, cultura e capacidade gerencial que sejam capazes de encarar resistências e superar obstáculos diante da complexidade peculiar desta área, bem como levar o tema ao conhecimento de gestores e profissionais que atuam nesta área para uma reflexão, despertar interesse e a possibilidade de ser aplicada na área hospitalar, levando para dentro dos hospitais um conceito de prestação de serviços humanizados 


\section{CONCLUSÃO}

O objetivo deste trabalho foi pesquisar, na visão de diferentes autores e estudiosos da temática, qual a efetiva contribuição da hotelaria hospitalar aos clientes da saúde e como ferramenta de humanização e marketing. Para tanto, conceituou-se marketing, marketing aplicado à saúde pública, hotelaria hospitalar; descreveu-se os valores e ações humanas agregados ao tratamento dispensado às pessoas recebidas como hóspedes, através dos serviços de Hotelaria Hospitalar; pesquisou-se a realidade do mercado e a necessidade de implantar os serviços de Hotelaria Hospitalar como uma estratégia inteligente para atender às exigências e às expectativas do cliente de saúde; finalmente, pesquisou-se a contribuição da Hotelaria Hospitalar no enfoque do atendimento e do acolhimento humanizado.

Nesse percurso, verificou-se que com a crescente exigência dos clientes da saúde por melhores estruturas e atendimento, os hospitais estão buscando adaptarse fisicamente e profissionalmente para atender as necessidades e desejos deste público tão exigente; que esse é o desafio das instituições de saúde empenhadas com a mudança, adaptando seu sistema de gestão com o objetivo de oferecer hospitalidade, além da hospitalização, fazendo com que a hotelaria hospitalar seja uma tendência irresistível para as instituições de saúde brasileiras interessadas em prestar o melhor atendimento ao seu cliente.

Isso porque, com a inserção da hospitalidade nos hospitais, predomina a humanização na prestação dos serviços e pode-se minimizar a dor do paciente, diminuir o seu tempo de internação e, consequentemente, contribuir para a sua cura.

A implantação da hotelaria hospitalar parcial ou na sua plenitude nos hospitais públicos é algo ainda difícil de alcançar quando comparado aos hospitais privados. A reestruturação administrativa e física para adaptação de um serviço de hotelaria no hospital público, pode provocar impacto, porém se houver metas estabelecidas, esta conquista pode se tornar realidade.

Além dos recursos financeiros, os hospitais públicos necessitam de uma mudança paradigmática profunda, uma mudança que implica a transição de uma organização administrativa para encarar o grande desafio: que o ato de servir e pôr-se, efetivamente, à disposição da sociedade volta a se converter no perfil distintivo de quem opta por esta vocação e que a faz administrando os recursos com eficiência. 
De acordo com a Organização Pan-Americana da Saúde (2004, p.191),

\begin{abstract}
"O caminho da modernização exige a conversão em um objetivo comum: a modernização não é um elemento isolado; também não é um fim em si mesmo, senão tão somente um instrumento por meio do qual se pretende reduzir a brecha que separa o que a cidadania necessita e o que a sociedade organizada pode prover".
\end{abstract}

A iniciativa de implantação de um serviço de hotelaria nos hospitais públicos é prioridade: visando acolher e acomodar o cliente/acompanhante SUS, sem recursos muitas vezes para manter o básico para higiene pessoal, justifica a implantação desse serviço de apoio que acomoda e orienta e estabelece um elo de parceria entre o cliente, que é o nosso formador de opinião e as normas institucionais. E sob a coordenação da comissão de hotelaria está o papel de identificar oportunidades e ameaças, contribuindo para a efetividade dos resultados e humanização do ambiente.

A hotelaria hospitalar propicia uma gestão participativa, onde os clientes e colaboradores se interagem de uma forma efetiva e buscam por meio desta interação a qualidade, a eficiência e a eficácia na prestação de serviços. Dinamiza e racionaliza os serviços de apoio dos hospitais, cria e implementa programas e projetos de humanização hospitalar e disponibiliza aos clientes serviços de hotelaria que contribuem para minimizar a tensão do ambiente e propicia maior conforto e bem estar.

Concluiu-se, enfim, que a hospitalidade deve fazer parte da cultura institucional e estar incorporada no comportamento e atitudes de todos os colaboradores e que as instituições de saúde, devem avançar e abraçar essa idéia inovadora que é a implantação da hotelaria hospitalar, visando à recuperação, a satisfação, a qualidade e humanização do ambiente do seu cliente externo. 


\section{REFERÊNCIAS}

AGÊNCIA NACIONAL DE VIGILÂNCIA SANITÁRIA. Processamento de roupas de serviços de saúde: prevenção e controle de riscos. Brasília: ed. Anvisa, 2007.

BELLO, Â. A. Introdução à fenomenologia. Bauru, SP: Educs, 2006.

BOEGER, M. A. Gestão em hotelaria hospitalar. São Paulo: Atlas, 2003.

BOEGER, M. A. Gestão em hotelaria hospitalar. São Paulo: Atlas, 2005.

BRASIL, M. S. Manual de lavanderia hospitalar. Brasília, 1986.

BRASIL. M. S.. Manual de Humanização. Disponível em: http//www.portalhumaniza.org.br, Acessado em 03.05.2009

CAMARGO, L. O. L. Turismo, hotelaria e hospitalidade. In DIAS, M. C. (Org) Hospitalidade: Reflexões e Perspectivas. São Paulo: Manole, 2002.

CÂNDIDO, I; MORAES, O. D.; VIEIRA, E.V. Hotelaria hospitalar: um novo conceito no atendimento ao cliente da saúde. Caxias do Sul, RS: Educs, 2004.

CASTRO, R. M.S. e CHEQUER, S.S. I. Serviço de processamento da roupa hospitalar: gestão de funcionamento. Viçosa: UFV, 2001.

FIGUEIREDO, N.M.A. Fundamentos, Conceitos, situações e Exercícios. São Paulo: Difusão, 2003

GODOI, A. F.. Hotelaria hospitalar e humanização no atendimento em hospitais: pensando e fazendo. São Paulo: ícone, 2004.

GUIMARÃES, N. V. R. Hotelaria hospitalar: uma visão interdisciplinar. São Paulo: Atheneu, 2007.

ISMAEL, S.M.C. Temas de prevenção, ensino e pesquisa que permeiam o contexto hospitalar. São Paulo: Casa do Psicólogo Livraria e Editora Ltda, 2005. 
ISMAEL, S.M.C. A prática psicológica e sua interface com as doenças. São Paulo: Casa do Psicólogo Livraria e Editora Ltda, 2005.

KONKEWICZ, L.R. Prevenção e controle de infecção relacionada ao processamento de roupas hospitalares. Disponível em: http:// www.cih.com.br/lavanderiahospitalar.htm, acesso em: 03/05/2009.

KOTLER, P. Administração de Marketing. Prentice Hall Brasil, 2006.

KOTLER, et al., Marketing de Serviços Profissionais. Manole, 2002.

LAMBERT, E. A. Terapia do Riso: a cura pela alegria. São Paulo: Ed. Pensamento, 1999.

MASLOW, A.H. Uma Teoria da motivação humana. Rio de janeiro: saraiva 1975

MEZZOMO, A. A. Lavanderia Hospitalar - Organização e técnica. São Paulo: CEDAS, 1980.

MORAES O. D.; CÂNDIDO,Í.. Hotelaria hospitalar: Um novo conceito no atendimento ao cliente da saúde. In. Manual do Programa Nacional de Humanização da Assistência Hospitalar. Caxias do Sul: Educs, 2004.

Organização Pan-Americana da Saúde. A transformação da Gestão de hospitais na América Latina e Caribe. Brasília: OPAS/OMS, 2004.

SCHIAVO, M. R. Conceito \& Evolução do Marketing Social. Disponível em: http:// www.socialtec.com.br, acesso em: 03/5/2009.

TARABOULSI, F. A. Serviços hospitalares: teoria e prática: compreender para atender e surpreender. São Paulo: Reichmann \& Autores Editores, 2005.

TARABOULSI, F., A. Administração de hotelaria hospitalar. São Paulo: Atlas, 2009.

TRIVIÑOS, A. N.S. Introdução à pesquisa em ciências sociais: a pesquisa qualitativa em educação: a prática reflexiva. São Paulo: Atlas, 1987. 
VERGARA, S.C. Começando a definir a metodologia. In:

Projetos e relatórios de pesquisa em administração. São Paulo: Atlas, cap 4. 2000.

Sites.

www.marketingpower.com. AMA- American Marketing association- Nova definição de 2005 (acessado em 13.11.09).

www.cih.com.br/lavanderiahospitalar.htm . Konkewicz.( acessado em 03.12.09)

www.abifcc.org.br/noti10012006. Hospital Erasto Gaertner- Curitiba,PR,2006 (acessado em 15.03.10) 